Article

\title{
Design, Modeling, Additive Manufacturing, and Polishing of Stiffness-Modulated Porous Nitinol Bone Fixation Plates Followed by Thermomechanical and Composition Analysis
}

\author{
Ahmadreza Jahadakbar ${ }^{1}$, Mohammadreza Nematollahi ${ }^{1} \mathbb{1}$, Keyvan Safaei $^{1}$, Parisa Bayati ${ }^{1}$, \\ Govind Giri ${ }^{1}$, Hediyeh Dabbaghi ${ }^{1}$, David Dean ${ }^{2}$ and Mohammad Elahinia ${ }^{1, *(D)}$ \\ 1 Department of Mechanical, Industrial, and Manufacturing Engineering, The University of Toledo, Toledo, \\ OH 43606, USA; Ahmadreza.Jahadakbar@rockets.utoledo.edu (A.J.); mnemato@rockets.utoledo.edu (M.N.); \\ Keyvan.SafaeiBaghbaderani@rockets.utoledo.edu (K.S.); Parisa.BayatiMalayeri@rockets.utoledo.edu (P.B.); \\ Govind.Giri@rockets.utoledo.edu (G.G.); hdabbag@rockets.utoledo.edu (H.D.) \\ 2 Department of Plastic and Reconstruction Surgery, The Ohio State University, Columbus, OH 43210, USA; \\ David.Dean@osumc.edu \\ * Correspondence: mohammad.elahinia@utoledo.edu; Tel.: +1-419-530-8224
}

Received: 30 December 2019; Accepted: 16 January 2020; Published: 19 January 2020

\begin{abstract}
The use of titanium bone fixation plates is considered the standard of care for skeletal reconstructive surgery. Highly stiff titanium bone fixation plates provide immobilization immediately after the surgery. However, after the bone healing stage, they may cause stress shielding and lead to bone resorption and failure of the surgery. Stiffness-modulated or stiffness-matched Nitinol bone fixation plates that are fabricated via additive manufacturing (AM) have been recently introduced by our group as a long-lasting solution for minimizing the stress shielding and the follow-on bone resorption. Up to this point, we have modeled the performance of Nitinol bone fixation plates in mandibular reconstruction surgery and investigated the possibility of fabricating these implants. In this study, for the first time the realistic design of stiffness-modulated Nitinol bone fixation plates is presented. Plates with different levels of stiffness were fabricated, mechanically tested, and used for verifying the design approach. Followed by the design verification, to achieve superelastic bone fixation plates we proposed the use of Ni-rich Nitinol powder for the AM process and updated the models based on that. Superelastic Nitinol bone fixation plates with the extreme level of porosity were fabricated, and a chemical polishing procedure used to remove the un-melted powder was developed using SEM analysis. Thermomechanical evaluation of the polished bone fixation plates verified the desired superelasticity based on finite element (FE) simulations, and the chemical analysis showed good agreement with the ASTM standard.
\end{abstract}

Keywords: Nitinol; additive manufacturing; patient specific implant; bone fixation plate; porous structure; stiffness-modulation

\section{Introduction}

Oral cancer, infection, tumors, and trauma may lead to structural defects in the mandible either aesthetically or functionally, which needs to be treated through reconstructive surgery. In this surgery, the defective bone is removed and replaced with a bone graft using bone fixation plates and screws. Graft mispositioning causes serious problems and so the reconstruction of segmental bony defects needs to be accurate to provide facial contour with proper height and width of the bone and restore jaw continuity [1]. To this end, fixation plates, most commonly made of Ti-6AL-4V (Ti64), or generally 
known as titanium), are used to provide stabilization and immobilization of the bone graft. Although Ti64 bone fixation plates provide a high level of immobilization immediately after the surgery, they may lead to stress shielding (bone resorption) or stress concentrations (device failure). Due to the stiffness-mismatch between the Ti64 bone plates and the bone, stress shielding occurs on the adjacent bone tissue, based on the bone remodeling theory, which leads to bone resorption. Followed by continuous bone resorption on the adjacent bone, the stress levels on the bone plates increase and this may lead to the failure of the plate, bone, and the surgery.

As a solution, our group has proposed and introduced a new generation of bone fixation plates that are stiffness matched to the bone tissue and are fabricated via additive manufacturing [2-7]. Stiffness modulation and the matching is achieved via replacing the Ti64 with Nitinol, as well as incorporating engineered porosity to the bone fixation plates. Nitinol (NiTi), is a biocompatible, low stiffness, shape memory alloy, which benefits from interesting features such as superelasticity and shape memory. Nitinol has been already used in many industrial applications as well as biomedical applications [8-14]. In addition to the inherent low stiffness, NiTi superelastic behavior can be made to be very similar to bone tissue. This makes it a great candidate for bone fixation and other skeletal reconstruction applications. Although NiTi has a relatively lower level of stiffness, it still provides a higher level of stiffness in comparison to the bone tissue. We have shown that by introducing an engineered level and type of porosity to a bone fixation plate, one is able to further reduce the stiffness of NiTi bone fixation plates and reach the level of bone tissue $[15,16]$. We have also shown that the additive manufacturing method, in the form of selective laser melting (SLM), can be used for the fabrication of porous NiTi bone fixation plates [17,18]. Although we have shown successful results in different sections of this novel approach, in this article with a focus on the fabrication approach (i.e., additive manufacturing), we characterized the fabricated parts and updated the design methodology based on that.

Advances in AM techniques and process development, we have been encouraged by many researchers to study the specific fabrication of biomedical components, which were hard or impossible to fabricate by conventional methods (e.g., machining, forging, etc.) in some cases. The use of AM allows many opportunities not open to conventional methods, such as patient-specific implants with tailorable properties [19-22], complex geometries [16], and better accuracies [23]. Rana et al. fabricated a titanium patient-specific implant for reconstruction of the unilateral orbital fracture using selective laser melting and compared it with a pre-bent titanium mesh, which was manually bent to the desired shape. The results of 34 cases showed a higher degree of accuracy of reconstruction in the case of SLM fabricated implants [23]. A custom made SLM titanium implant used in [24] to treat post-traumatic zygomatic deficiency showed no sign of infection after one year with good integration, suggesting SLM implants are an effective approach for alloplastic craniomaxillofacial bone reconstruction. A clinical study of ten patients who used 3D-printed patient-specific Ti plates showed facilitation in jaw reconstructive surgery as well as higher accuracies [25]. Most of the research in this area has been conducted on Ti-6AL-4V plates and/or implants. In recent years, additive manufacturing of NiTi alloys are getting more attention for the fabrication of complex shapes and geometries [26-30]. This is mostly due to the freedom of fabrication and the superior properties of NiTi, as mentioned earlier. However, most of the research is fundamental, aimed at finding optimal fabrication process parameters and their effects on the part's properties [31], lattice structures [18], corrosion behavior [3], modeling [32], and biocompatibility [33]. It should also be noted that all the SLM fabricated porous structures in the literature have been evaluated only in compression mode and no study, as far as we know, has been done on a realistic stiffness-matched porous bone fixation plate, which is under tension.

In this paper, standard-shaped 4-hole bone fixation plates with modulated levels of stiffness were modeled and simulated in a finite element (FE) model. To validate the design and modeling procedure, designed bone fixation plates with different levels of porosity were fabricated via selective laser melting using Ni50.1Ti powder and mechanically tested under tension. After validation of the modeling procedure, to achieve superelastic behavior, Ni-rich Ni50.8Ti powder was used for the fabrication of 
the second generation of the bone fixation plates. Thermomechanical and composition analysis of the superelastic stiffness-matched porous bone fixation plates were discussed and a proper methodology for polishing and removing the un-melted powder is then proposed.

\section{Materials and Methods}

In order to test the bone fixation plates using a standard tensile setup, a straight (not curved) standard 4-hole bone fixation plate geometry, as shown in Figure 1a, was used for the fabrication of the bone fixation plates in this paper. For the first series of fabrication, bone fixation plates with a 3-mm thickness profile were designed and fabricated. At the second stage of the project, after validating the FE model, to characterize the bone fixation plates with the critical level of porosity and the most complex geometry, bone fixation plates with $1.5 \mathrm{~mm}$ thickness were fabricated. In order to impose porosity on the bone fixation plates, a cubic pore cell as shown in Figure 1b, was used. The cube was $1 \mathrm{~mm}$ and by changing the thickness of the sides, the level of porosity was modulated. A thin $0.5 \mathrm{~mm}$ cover as shown in Figure 1 was also designed to cover the bone fixation plate and provide the required support for screws.

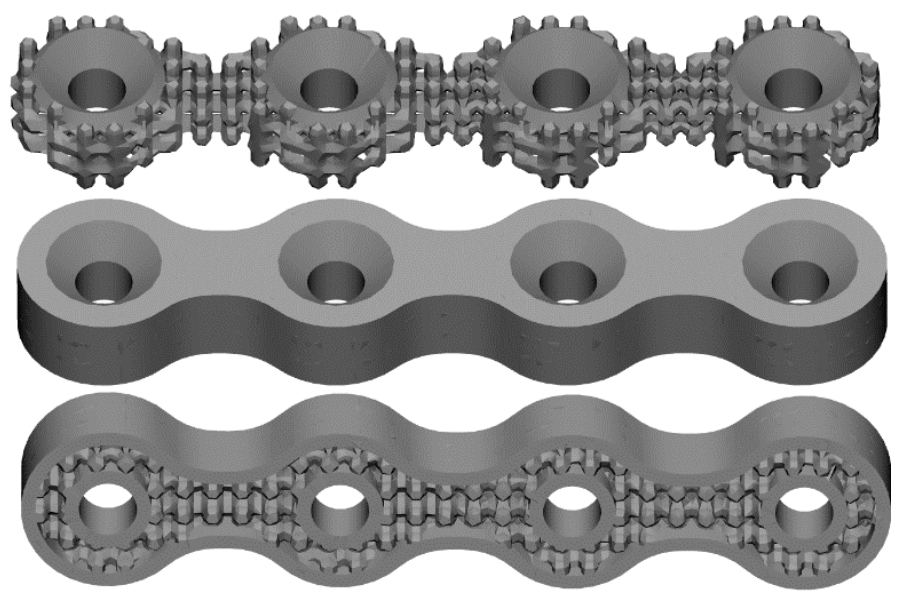

(a)

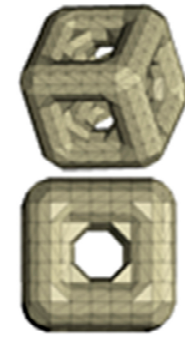

(b)

Figure 1. (a) Overall geometry of the fabricated bone fixation plates and (b) unit pore cell used for creating the porous bone fixation plates.

Two batches of Ni50.1Ti (at. \%) and Ni50.8Ti (at. \%) ingot were gas atomized using an electrode induction-melting gas atomization (EIGA) by TLS Technik GmbH (Bitterfeld, Germany) to make powder. The powder was sieved to produce particle sizes from 20 to $75 \mu \mathrm{m}$. The components of NiTi were produced using an SLM machine (Phenix Systems PXM, [3D Systems], Rock Hill, SC, USA). Our PXM SLM machine has a $300 \mathrm{~W}$ Ytterbium fiber laser with a wavelength of $1070 \mathrm{~nm}$ and a spot diameter of $80 \mu \mathrm{m}$ that yields a Gaussian (TEM00) profile. To lessen the impurities in the manufactured samples, the oxygen level in the fabrication chamber was controlled to be less than $800 \mathrm{ppm}$. There are two series of SLM fabrication process parameters, which are shown in Table 1. The standard dog-bone samples of Ni50.8Ti with the gauge length of $20 \mathrm{~mm}$, gauge the width of $3 \mathrm{~mm}$, and thickness of $2 \mathrm{~mm}$ were fabricated for capturing the mechanical properties of as-fabricated SLM parts.

Table 1. The process parameters (PPs) of two series of selective laser melting (SLM) fabrication.

\begin{tabular}{cccccc}
\hline ID & Powder & $\begin{array}{c}\text { Laser Power } \\
(\mathbf{P} ; \mathbf{W})\end{array}$ & $\begin{array}{c}\text { Scanning Speed } \\
(\mathbf{V} ; \mathbf{~} \mathbf{m m} / \mathbf{s})\end{array}$ & $\begin{array}{c}\text { Hatch Spacing } \\
\mathbf{( H ;} \boldsymbol{\mu m})\end{array}$ & $\begin{array}{c}\text { Layer Thickness } \\
(\mathbf{t} ; \boldsymbol{\mu m})\end{array}$ \\
\hline$\# 1$ & Ni50.1Ti & 250 & 1250 & 120 & 30 \\
$\# 2$ & Ni50.8Ti & 250 & 1250 & 80 & 30 \\
\hline
\end{tabular}


A Perkin-Elmer (Waltham, MA, USA) Pyris 1 differential scanning calorimetry (DSC) was used to identify the transformation temperatures (TTs) from -90 to $100{ }^{\circ} \mathrm{C}$ with a heating/cooling rate of $10{ }^{\circ} \mathrm{C} / \mathrm{min}$ in a nitrogen atmosphere by separating small portions of samples ranging from 30 to $45 \mathrm{mg}$. The standard tensile samples were tested with $25 \mathrm{kN}$ TestResources 910 Series Servohydraulic fatigue test machine (TestResources, Shakopee, MN, USA). A BOSE ElectroForce 3330 machine (TA Instruments, New Castle, DE, USA) was employed to test the bone fixation plates. All samples were loaded with a strain rate of $10^{-4}\left(\mathrm{~s}^{-1}\right)$ to make sure of isothermal condition. All tests were performed at room temperature (RT). A 2D digital image correlation (DIC) system (correlated solutions, Irmo, SC, USA) by Correlated Solutions, which uses a 5-megapixel camera, a Tonika $100 \mathrm{~mm}$ lens, and VIC_2D software was employed to measure the strain. The samples were painted with black and white speckle pattern for DIC measurement. The chemical analyses were performed on the SLM bone fixation plates according to ASTM 2063 standards (Table 2). Two different etching solutions (Table 3) and three different exposing times $(2,4$, and $6 \mathrm{~min})$ were utilized to chemically polish the superelastic porous bone fixation plates [34-36]. To evaluate the polishing procedure a FEI Quanta 3D FEG scanning electron microscopy (SEM, Thermo Scientific, Waltham, MA, USA) was used.

Table 2. ASTM 2063 test method description.

\begin{tabular}{cc}
\hline Test Method & Description \\
\hline ASTM E1409-13 & Inert gas fusion for oxygen and nitrogen \\
ASTM R146-83 & Vacuum hot extraction for hydrogen \\
ASRM E1941-16 & Combustion infrared detection for carbon \\
ASTM E1097-12 & Direct current plasma emission spectroscopy for all other elements \\
\hline
\end{tabular}

Table 3. The chemical composition of two etching solutions used for chemical polishing.

\begin{tabular}{ccc}
\hline Etching Solution & Chemical Composition & Ratio (HF:HNO $\left.\mathbf{H N}_{3}: \mathbf{H}_{\mathbf{2}} \mathbf{O}\right)$ \\
\hline Solution 1 & $\mathrm{HF}(10 \%), \mathrm{HNO}_{3}(40 \%), \mathrm{H}_{2} \mathrm{O}(50 \%)$ & $1: 4: 5$ \\
Solution 2 & $\mathrm{HF}(5 \%), \mathrm{HNO}_{3}(50 \%), \mathrm{H}_{2} \mathrm{O}(45 \%)$ & $1: 10: 9$ \\
\hline
\end{tabular}

\section{Modeling}

The bone fixation plates that we prepared were $3 \mathrm{~mm}$ thick with five different levels of porosity (bulk (0\%), 17\%, 20\%, 24\%, 27\%, and 30\%) were designed based on the methodology explained in the methods section. The STL file of designed bone fixation plates was re-meshed and proper volume meshes (10-node tetrahedral elements (C3D10)) were created and verified in a mesh convergence study. The final volume meshes were exported as INP files and imported to Abaqus (V2019, Dassault Systems; Providence, RI, the USA for finite element modeling). An Abaqus user-defined material subroutine (UMAT) developed based on the micro-plane theory [37-39] was used for capturing the mechanical behavior of the NiTi bone fixation plates. The UMAT is capable of simulating both superelastic and shape memory effects of shape memory alloys under multiaxial loading conditions [15] and requires the thermomechanical properties of the standard coupons (e.g., Young's modulus for austenite and martensite, transformation temperatures, critical stresses, etc.) as the input. More details on the utilized UMAT can be found elsewhere [40].

Thermomechanical properties of Ni50.1Ti from [41] were used for tuning the UMAT mentioned above. Followed by preparing the FE model, the uniaxial tensile test of the bone fixation plates was simulated. The load-displacement response of the bone fixation plates under tensile loading is summarized in Figure 2. As it is seen in Figure 2, adding different levels of porosity to the bone fixation plates alters the stiffness of the plates and can be used for achieving engineered levels of stiffness. As the next step, the simulated bone fixation plates were fabricated and used for validating the FE simulations. 


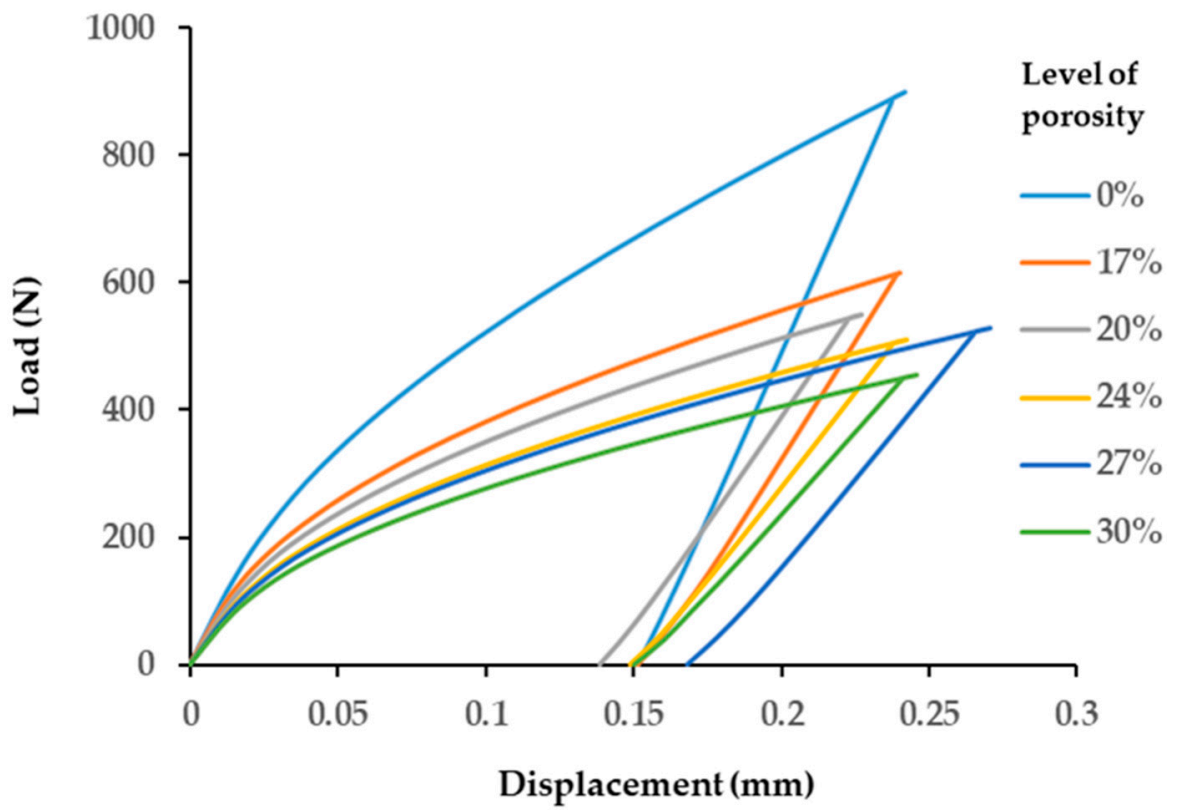

Figure 2. The load-displacement response of simulated plates with different levels of porosity.

\section{Mechanical Evaluation}

To validate the simulation results, a series of uniaxial tensile mechanical testing on the first series of bone fixation plates with different levels of porosity was performed. All the parts were fabricated horizontally and on a support structure. As shown in Figure 3, the same trend was observed for the load-displacement response of the fabricated bone fixation plates, so that the stiffness of the plate decreased as the level of porosity goes up. For making a comparison between experimental and simulation data, the results of two extreme conditions (bulk bone fixation plate, 30\% porosity) were plotted in Figure 4, and as it can be seen, the simulation results are in good agreement with experimental data.

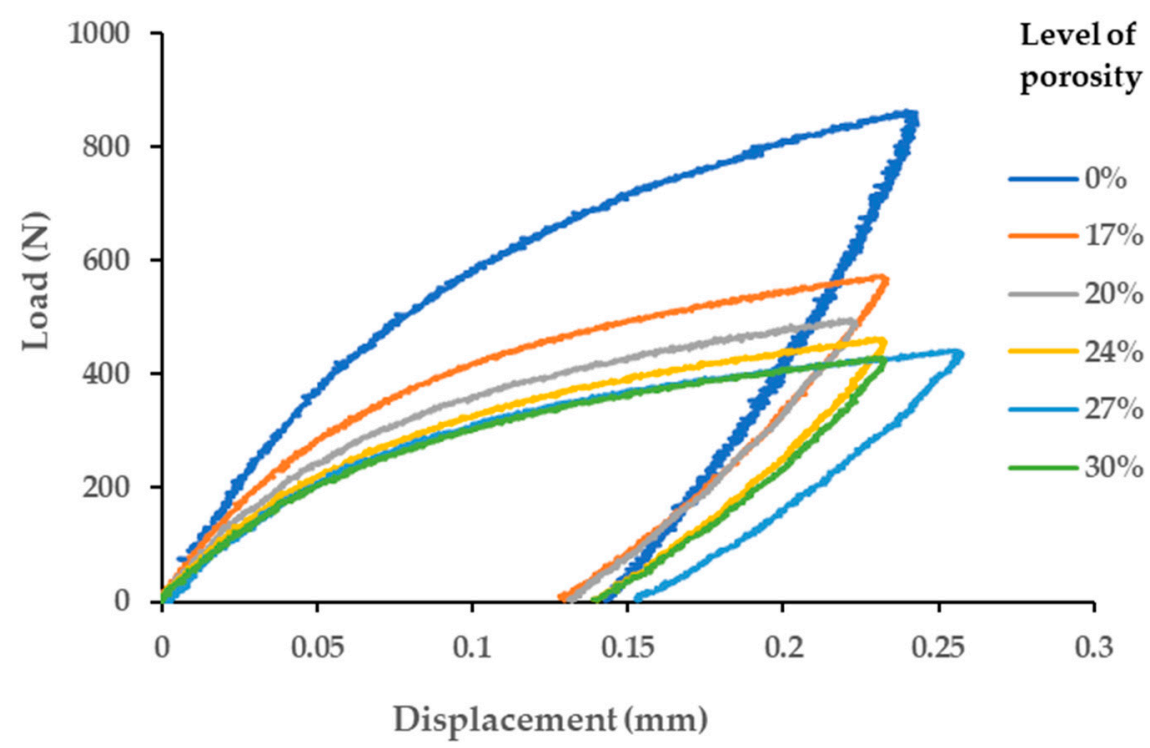

Figure 3. The experimental result of an SLM NiTi fixation plate with different porosity levels under tension. 

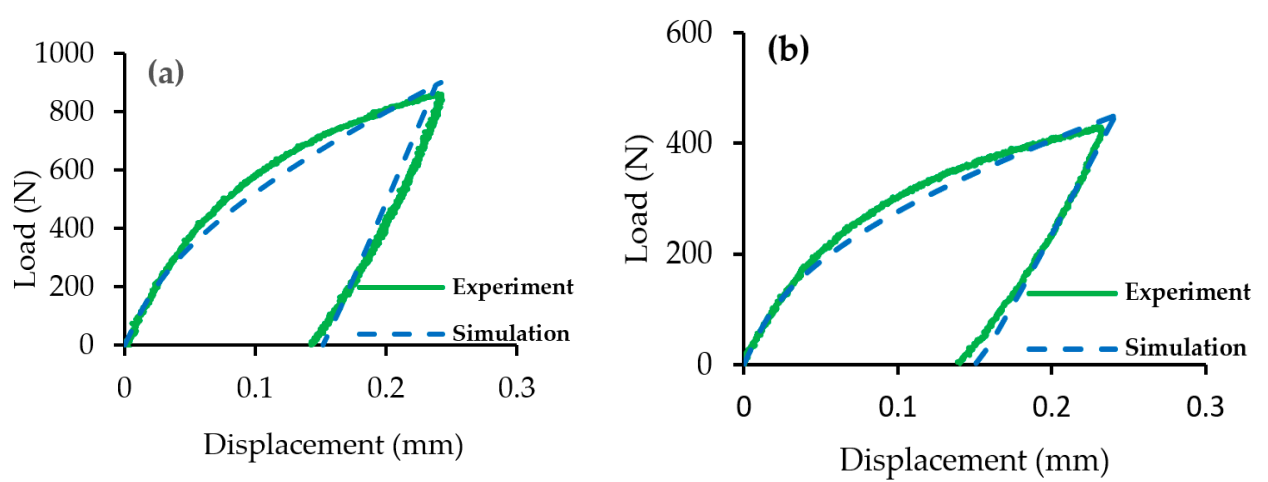

Figure 4. Comparison of experimental and simulation results of (a) bulk plate ( $0 \%$ of porosity) and (b) the plate with the porosity of $30 \%$.

As was shown in the previous sections, the stiffness of the bone fixation plates, regardless of their overall geometry, can be modulated and tuned to a specific level based on the stiffness of the bone to which it will be attached. However, based on our reading of the clinical literature, it would be useful to be able to create superelastic bone fixation plates in order to recover a larger level of deformation and insure compression between adjacent bone segments that are healing. The superelasticity of bone fixation plates could also act as a shock absorber to prevent failure of the implant in case of short term high impact forces or extreme, but unusual, loading conditions (i.e., failsafe). In addition, it is sometimes useful to apply constant pressure where the bone fixation plates are used. Contact pressure (compression) created by the bone fixation plate should improve the healing procedure and reduce the micromotions that would rip apart the healing region. However, as it can be seen in the load-displacement response (Figures 3 and 4), the fabricated bone fixation plates did not exhibit superelasticity and a noticeable level of recoverable strain. Therefore, after validation of the design, modeling, and fabrication procedure, we replaced the Ni50.1Ti powder used for the SLM procedure with a more Ni-rich powder (Ni50.8Ti) to reduce the transformation temperatures and create superelastic bone fixation plates. The next section discussed the details of the transition to superelastic bone fixation plates.

\section{Superelastic Stiffness-Modulated Bone Fixation Plates}

In order to investigate the superelastic response of bone fixation plates, only bone fixation plates with the most complex geometry (minimum thickness $=1.5 \mathrm{~mm}$ ) and an extreme level of porosity (i.e., $46 \%$ ) was considered. To create a realistic geometry for the bone fixation plate, a 4-hole $1.5 \mathrm{~mm}$ thick bone fixation plate as shown in Figure 5a was provided by Stryker (Kalamazoo, MI, USA). The plate was then scanned using a micro computed tomography (micro-CT), and its CAD model was created (Figure $5 b)$. Using the same methodology explained earlier, the porosity $(0.6 \mathrm{~mm}$ pore cells) and a covering thin-wall structure $(0.2 \mathrm{~mm}$ ) added to the CAD model (Figure $5 \mathrm{c}, \mathrm{d}$ ). After creating the final CAD model for the porous plate, by following the previous procedure, an FE model for simulating the tensile behavior as well as an STL file for the SLM fabrications was created. In order to accurately characterize the tensile behavior of the Ni50.8Ti bone fixation plates, standard tensile samples were also designed and prepared for fabrication in addition to the bone fixation plates. Figure 6 shows the fabricated bone fixation plates immediately after fabrication and before the support removal procedure. Localized and overall thermomechanical behavior of the standard tensile coupon as well as the bone fixation plates, is discussed in the next section. 
(a)

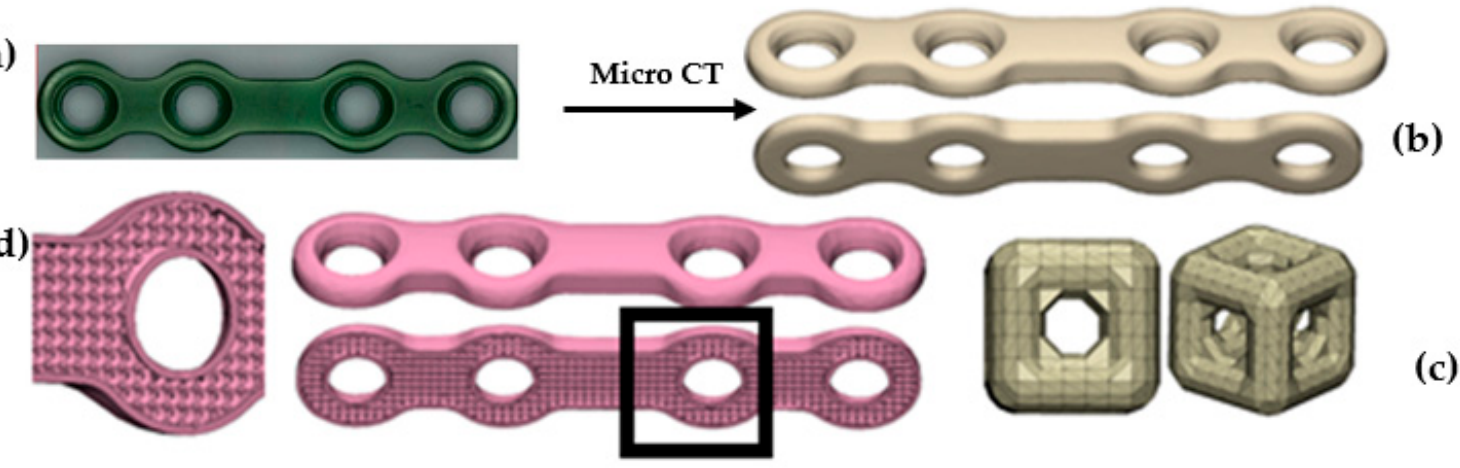

Figure 5. Preparation of a bone fixation plate with an extreme level of porosity and the realistic geometry. (a) Conventionally fabricated Ti64 bone fixation plate with standard geometry used as the reference, (b) reconstructed CAD through Micro CT, (c) porosity cell, and (d) porous bone fixation plate.

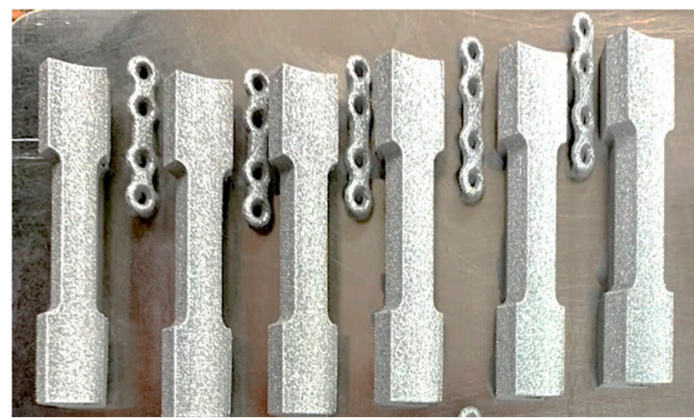

Figure 6. NiTi porous bone fixation plates and tensile samples fabricated via the SLM method.

\subsection{Thermomechanical Behavior}

DSC results, as well as the transformation temperatures of Ni-rich porous bone fixation plates, standard dog-bone samples, and powder particles, are shown and reported in Figure 7 and Table 4, respectively. For the porous plate, the DSC samples were cut from three different regions as shown in Figure 6. Based on the location that the DSC samples were cut from, different transformation temperatures were achieved. The transformation temperatures (TTs) variation can be explained by the nature of the SLM process and the complex shape of the porous plates that resulted in different thermal histories. The effect of different thermal histories during the SLM process can be compared to different heat treatment procedures, which are performed on the final parts. As different heat treatment procedures lead to different TTs, for instance, different thermal histories also can lead to non-homogeneous microstructure [42] as a result, different TTs. This non-homogeneity and variation in TTs variation indicate the necessity of the heat treatment as a post-processing procedure for the as-fabricated samples for creating a homogeneous part. In this study, we did not optimize the heat treatment procedure for the bone fixation plates. That will be studied at a later time.

Table 4. The transformation temperatures (TTs) of powder, dog-bone, and the porous samples.

\begin{tabular}{ccccc}
\hline Sample & $\mathbf{M}_{\mathbf{s}}\left({ }^{\circ} \mathbf{C}\right)$ & $\mathbf{M}_{\mathbf{f}}\left({ }^{\circ} \mathbf{C}\right)$ & $\mathbf{A}_{\mathbf{s}}\left({ }^{\circ} \mathbf{C}\right)$ & $\mathbf{A}_{\mathbf{f}}\left({ }^{\circ} \mathbf{C}\right)$ \\
\hline Powder & 10.2 & -46.6 & -16.9 & 33.1 \\
Porous \#1 & 12.89 & -57.08 & -15.82 & 33.85 \\
Porous \#2 & 0.62 & -56.09 & -15.53 & 22.35 \\
Porous \#3 & 2.34 & -54.36 & -18.72 & 17.74 \\
Dog-bone & 2.14 & -60.06 & -15.10 & 26.96 \\
\hline
\end{tabular}




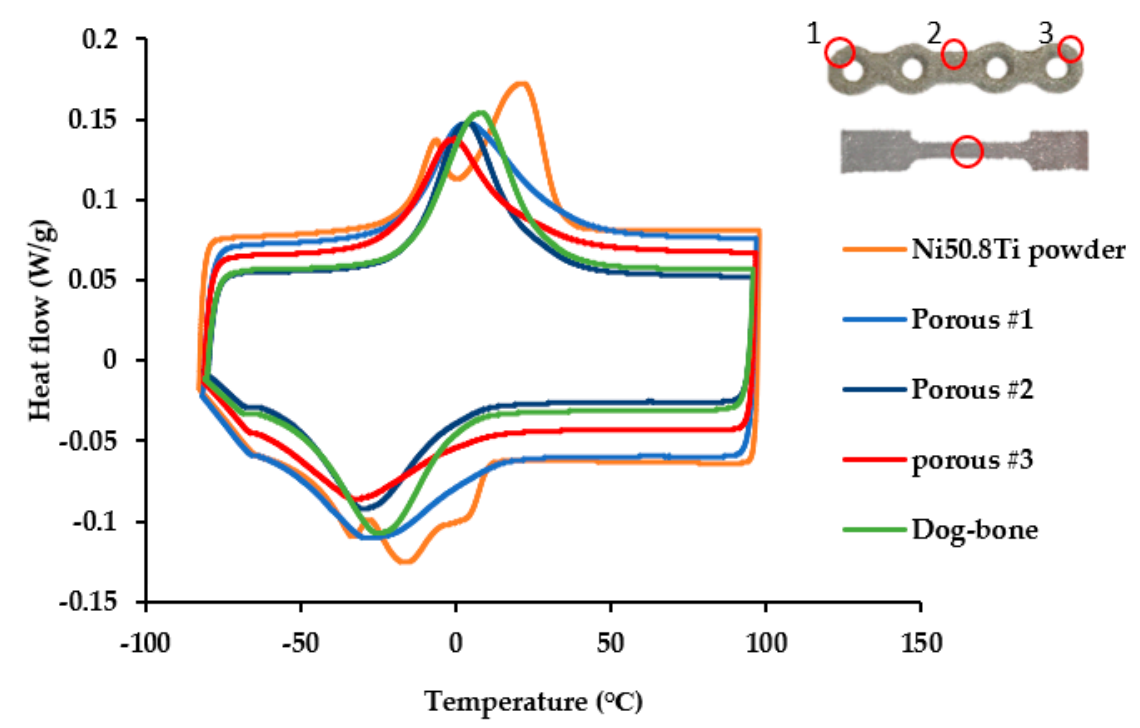

Figure 7. The differential scanning calorimetry (DSC) results of the as-fabricated porous bone fixation plate from three different locations, the dog bone sample, and Ni50.8Ti powder.

To measure the material properties of the fabricated Ni-rich bone fixation plates and updating the FE model, two standard tensile samples were tested, and the results are shown in Figure 8. The first sample was loaded up to the failure with a low strain rate $\left(0.0001 \mathrm{~S}^{-1}\right)$ to maintain the isothermal condition. Based on the stress-strain plot of the first sample, a loading-unloading test on the second sample was designed. The second sample was loaded up to the end of the plateau region ( $3 \%$ strain) and then unloaded to zero loads. The transformation strain of $2.6 \%$ ( $81 \%$ of total strain) was achieved for the as-fabricated part under tension. The material showed around $0.6 \%$ of irrecoverable strain that could be a result of permanent strain (slip) or the locked-in detwinned martensite and can be recovered by heating [43].

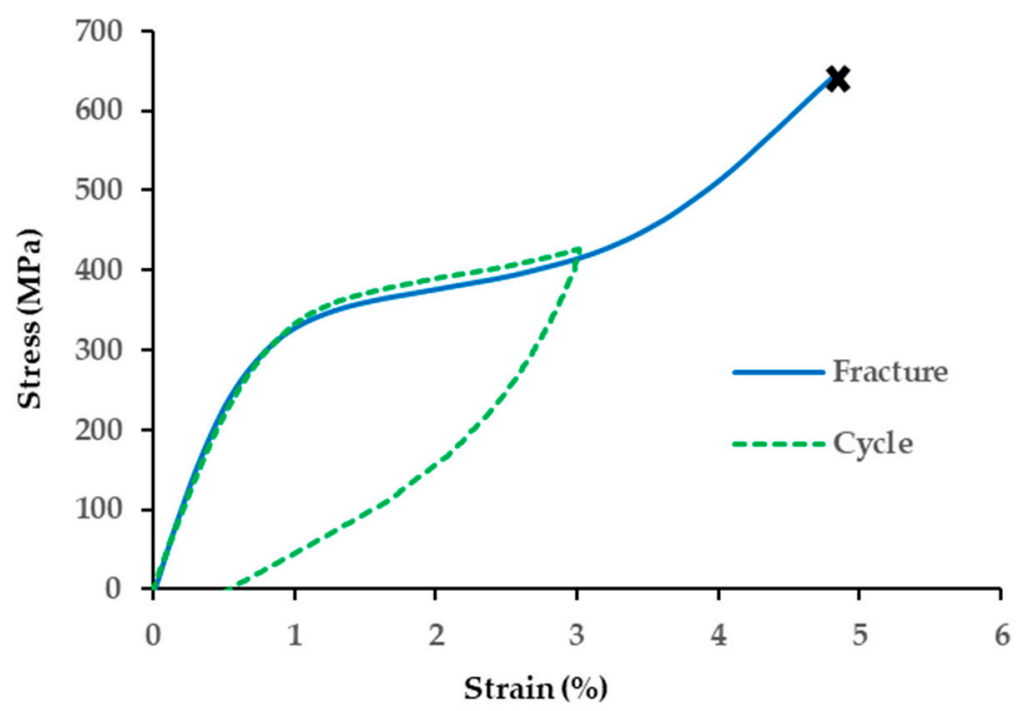

Figure 8. Stress-strain response of SLM dog-bone samples.

The mechanical properties of the as-fabricated material were reported in Table 5. The austenite (EA) and martensite (EM) modulus of elasticity were captured from loading and unloading plots, respectively. Followed by obtaining the material properties from the tensile samples, the Ni-rich bone fixation plate was simulated under tensile loading and unloading. The as-fabricated Ni-rich bone 
fixation plates were then mechanically tested under the same boundary conditions. Figure 9 shows the simulations as well as mechanical testing of the Ni-rich bone fixation plate.

Table 5. The mechanical properties of the standard tensile sample fabricated via SLM.

\begin{tabular}{cccc}
\hline $\mathrm{E}_{\mathbf{A}}(\mathrm{GPa})$ & $\mathrm{E}_{\mathbf{M}}(\mathrm{GPa})$ & Critical Stress Start (MPa) & Critical Stress Finish (MPa) \\
\hline 54 & 36 & 350 & 430 \\
\hline
\end{tabular}

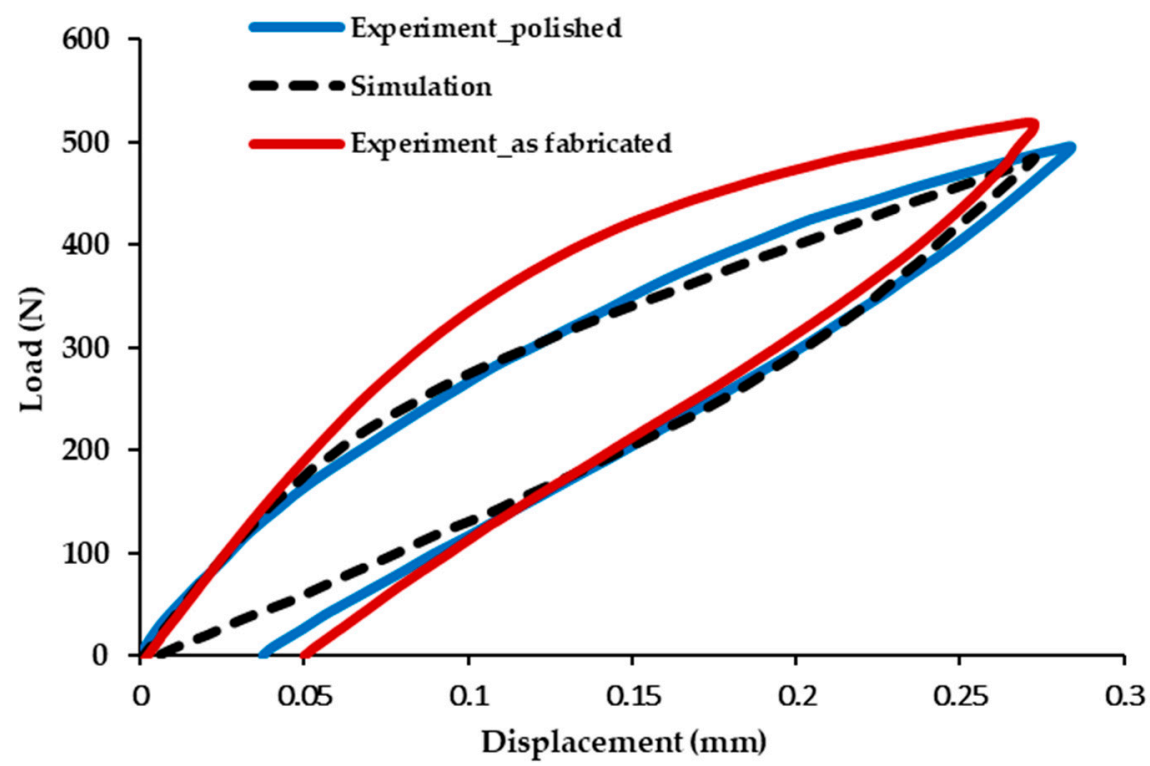

Figure 9. The load-displacement response of as-fabricated porous plate under tensile loading.

After inspection of the fabricated Ni-rich bone fixation plates, we observed a relative geometrical difference between the fabricated part and the CAD model. The size had increased in comparison with the previous case (i.e., the first series of bone fixation plates with larger dimensions). As reported by others [27], as-fabricated SLM fabricated parts could exhibit a geometrical expansion that is related to the laser width, melt pool diameter, and the fact that the part is surrounded by loose powder. The geometrical expansion of SLM-fabricated parts has a more significant effect when the parts include fine details that are close to the laser width. In the case of fabricating Ni-rich bone fixation plates with the extreme geometrical features, the geometrical expansion led to a higher difference with the simulations and the expected behavior. In addition, because of the fine features of the Ni-rich bone fixation plates, a higher amount of un-melted powder was trapped in the pore cells that affect the mechanical response and could affect their biocompatibility. Therefore, we have investigated a chemical polishing method to remove the un-melted powder particles attached to the parts, while not disturbing the fine geometries. This procedure is discussed in the next section. Eventually, the polished bone fixation plate that showed $23 \%$ mass loss was mechanically tested, and the load-displacement response is shown in Figure 9.

\subsection{Chemical Polishing}

Using the selective laser melting process, the complex geometries required for the bone fixation plates can be accurately fabricated. However, the SLM process often results in un-melted powders and other undesirable features that remain fused to the fabricated product. In order to remove the un-melted powder and to add a smooth finish to the part to improve performance (e.g., mechanical, cleaning, and sterilization reliability), a finishing process is required. Due to the complex geometries and fine porous structure of Ni-rich implants, current mechanical finishing processes are not efficient. They may damage the components and cannot reach fine internal features. Therefore, a chemical 
etching process was opted for. The chemical etching and finishing processes of additively manufactured nickel-titanium components is not well researched. Therefore, a series of tests were undertaken in order to better optimize the etching solution used for the bone fixation plates.

The tests consisted of two different etching solutions and three different times for submerging the components within those solutions (Table 3). The samples were cleaned in water using an ultrasonic bath for $5 \mathrm{~min}$ both before and after the chemical finishing process. Both solutions were composed of hydrofluoric acid $(\mathrm{HF})$, nitric acid $\left(\mathrm{HNO}_{3}\right)$, and purified distilled water $\left(\mathrm{H}_{2} \mathrm{O}\right)$. It is known that the HF in the etching solution act as a dissolvent while the $\mathrm{HNO}_{3}$ behaves as a passivator [44]. The distilled water is used to dilute the solution in order to prevent excessively rapid corrosion/material loss. The samples were submerged for $2 \mathrm{~min}, 4 \mathrm{~min}$, and $6 \mathrm{~min}$.

Figure 10 shows the results of the chemical etching process on the mass loss of the samples etched the two trialed solutions. Three bone-plate was etched within the etching solution 1 while three others were etched within the solution 2 . The mass loss increased proportionally with the time for both solutions. The results show that the second solution with reduced $\mathrm{HF}$ and increased $\mathrm{HNO}_{3}$, removed material at nearly twice the rate of solution 1 .

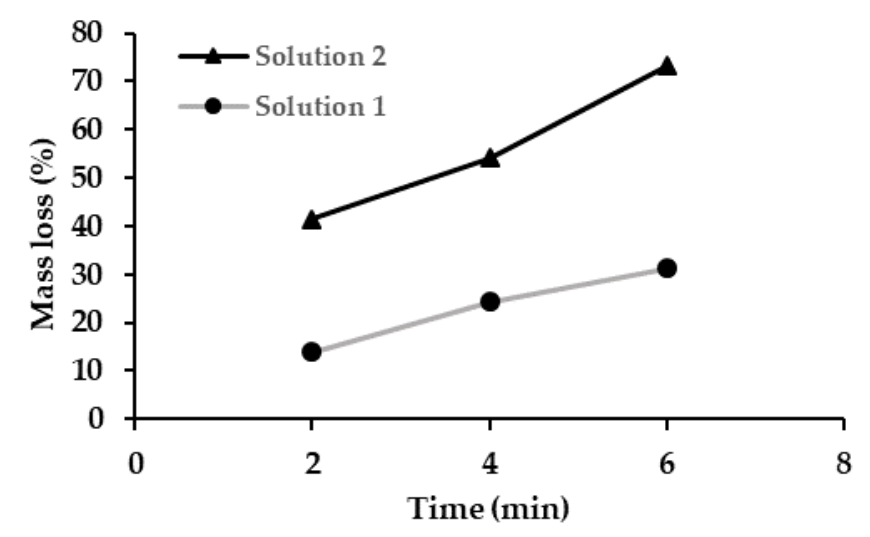

Figure 10. The percentage of mass loss versus time for two different etching solutions.

The effect of the etching procedure on the geometry, as well as the surface finish of the samples, is reflected in the SEM images in Figure 11. As it can be seen in the "As-built" sample, excessive un-melted powder is attached to the surface of the as-built sample and almost entirely covered the pores. S1-2, S1-4, and S1-6 show the SEM images of samples etched with solution 1 with the different durations of 2, 4, and $6 \mathrm{~min}$. The un-melted powder was partially removed on S1-2. S1-4 and S1-6 that were submerged for a long time showed the best result of the chemical polishing. In order to make a more accurate comparison on the effect of chemical polishing, the distance between the pores was measured and compared with the original distance on the CAD file. Based on this comparison, the size and geometry of S1-2 had the most consistency with the original CAD model, and therefore it was reported as the optimized polishing procedure. The polishing by solution 2 for $2 \mathrm{~min}$ (S2-2) was almost good but still more than required. While the polishing with solution 2 for 4 and 6 min (S2-4 and S2-6) was too aggressive and caused excessive degradation of the pore structures. 

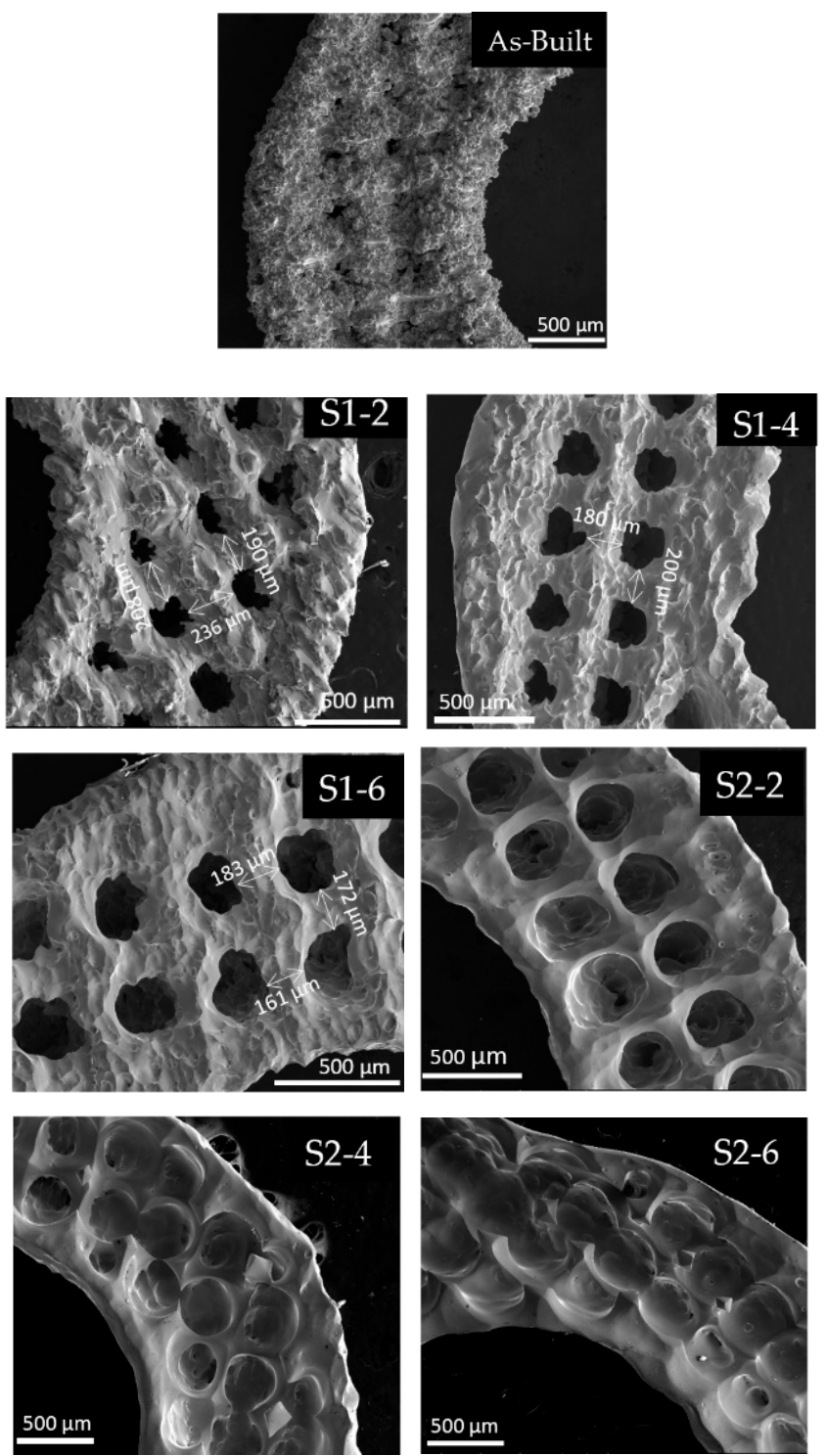

Figure 11. The SEM result of chemically polished porous plates under six different etching conditions.

\subsection{Chemical Composition Analysis}

Understanding the chemical composition of bone fixation plates is critical. Since this is a medical implant, strict controls are required to ensure biocompatibility (i.e., lack of toxicity). Analyzing and accounting for any precipitates or ion formation due to the additive manufacturing process is, therefore, a necessity. The results for our chemical analysis of these bone fixation plates is displayed in Table 6 . The elements analyzed were carbon $(\mathrm{C})$, hydrogen $(\mathrm{H})$, oxygen $(\mathrm{O})$, nitrogen $(\mathrm{N})$, nickel $(\mathrm{Ni})$, cobalt $(\mathrm{Co})$, copper $(\mathrm{Cu})$, chromium $(\mathrm{Cr})$, iron $(\mathrm{Fe})$, niobium $(\mathrm{Nb})$, and titanium $(\mathrm{Ti})$. The composition analysis is compared with the allowable values of nickel-titanium shape memory alloys for medical devices and surgical implants, as described in ASTM F 2063 [45]. The results show that the AM Nitinol compositions were within expected parameters with respect to total weight percentage. However, the nitrogen plus oxygen level was slightly above the acceptable ASTM requirement at this stage in our work. The cobalt, copper, chromium, nitrogen, carbon, hydrogen, and niobium were not present in a quantity sufficient to alter the predicted mechanical performance. Ratios of iron and oxygen were also low and do not present an obstacle to the performance and safety of these bone fixation plates. 
Table 6. The results of the chemical composition analysis.

\begin{tabular}{ccc}
\hline Element. & Composition (wt. \%) & ASTM F-2063 Composition Requirements (wt. \%) \\
\hline Nickel & 56.0 & $54.5-57.0$ \\
Carbon & 0.002 & $<0.050$ \\
Cobalt & $<0.0005$ & $<0.050$ \\
Copper & $<0.0005$ & $<0.010$ \\
Chromium & $<0.0005$ & $<0.010$ \\
Hydrogen & 0.0004 & $<0.005$ \\
Iron & 0.016 & $<0.050$ \\
Niobium & $<0.002$ & $<0.025$ \\
Oxygen & 0.058 & - \\
Nitrogen & $<0.005$ & - \\
Nitrogen + Oxygen & $<0.063$ & $<0.050$ \\
Titanium & Balance & Balance \\
\hline
\end{tabular}

\section{Conclusions}

The porous stiffness-modulated NiTi bone fixation plates with different levels of stiffness were designed and modeled via a FE analysis. It was shown that specific levels of stiffness could be achieved by introducing engineered levels of porosity to the bulk plate, and the mechanical properties can be captured using the properties of standard coupons. Due to the complex geometry of porous bone fixation plates, the SLM technique was employed to fabricate the NiTi plate. This methodology can be applied to complex geometries and plates as thin as $1.5 \mathrm{~mm}$. The as-fabricated parts were tested mechanically, and the experimental results were in a good agreement with the FE model. After modeling verification and confirming the design methodology, Ni-rich bone fixation plates were fabricated to achieve superelastic behavior. The DSC results of the porous Ni-rich bone fixation plate showed a small variation in TTs of different locations of the plates. Various thermal histories that the parts experienced during the SLM process were the main reason for the variation in TTs. Two tensile samples using Ni-rich powder were fabricated along with Ni-rich bone fixation plates and tested to measure the mechanical properties used for FE modeling. The as-fabricated porous Ni-rich bone-plate fixation was tested and the predicted superelastic behavior was achieved. In order to test methods to remove un-melted powder particles from the surface following AM, the bone-plates were chemically polished under six different conditions. SEM analysis revealed that an etching solution with a composition of $\mathrm{HF}(10 \%), \mathrm{HNO}_{3}(40 \%), \mathrm{H}_{2} \mathrm{O}(50 \%)$, and the effective time of $4 \mathrm{~min}$, was the optimal etching solution to remove un-melted powder particles. The chemical composition analysis of our Ni-rich SLM bone fixation plates confirmed that the composition was in a good agreement with the ASTM 2063 requirements.

Author Contributions: Conceptualization, M.E. and D.D.; additive manufacturing, M.N.; simulation and validation, A.J. and K.S.; characterization P.B., K.S., A.J., M.N., G.G. and H.D.; all authors contributed to the writing of initial draft and final draft and reviewed the manuscript. All authors have read and agree to the published version of the manuscript.

Funding: This research was partially funded by a grant from the Third Frontier (Ohio Development Office) of Ohio (grant \# TECG20170372).

Acknowledgments: The authors would like to acknowledge the financial support of the Ohio Third Frontier Technology Validation and Start-up Fund.

Conflicts of Interest: The authors declare no conflict of interest. 


\section{References}

1. Emam, H.A.; Stevens, M.R. Concepts in Bone Reconstruction for Implant Rehabilitation. In A Textbook of Advanced Oral and Maxillofacial Surgery; IntechOpen: London, UK, 2013.

2. Jahadakbar, A.; Moghaddam, N.S.; Amerinatanzi, A.; Dean, D.; Karaca, H.; Elahinia, M. Finite element simulation and additive manufacturing of stiffness-matched niti fixation hardware for mandibular reconstruction surgery. Bioengineering 2016, 3, 36. [CrossRef] [PubMed]

3. Ibrahim, H.; Jahadakbar, A.R.; Dehghan, A.; Moghaddam, N.S.; Amerinatanzi, A.; Elahinia, M. In vitro corrosion assessment of additively manufactured porous NiTi structures for bone fixation applications. Metals (Basel) 2018, 8, 164. [CrossRef]

4. Moghaddam, N.S.; Jahadakbar, A.; Amerinatanzi, A.; Elahinia, M.; Miller, M.; Dean, D. Metallic fixation of mandibular segmental defects: Graft immobilization and orofacial functional maintenance. Plast. Reconstr. Surg. Glob. Open 2016, 4, 858. [CrossRef] [PubMed]

5. Moghaddam, N.S.; Jahadakbar, A.; Amerinatanzi, A.; Skoracki, R.; Miller, M.; Dean, D.; Elahinia, M. Fixation release and the bone bandaid: A new bone fixation device paradigm. Bioengineering 2017, 4, 5. [CrossRef]

6. Jahadakbar, A.; Moghaddam, N.S.; Amerinatanzi, A.; Dean, D.; Elahinia, M. Mechanical Evaluation of the SLM Fabricated, Stiffness-matched, Mandibular Bone Fixation Plates. Tissue Eng. Part A 2017, 23, S141.

7. Chirani, S.A.; Barati, M.; Saint-Sulpice, L.; Bayati, P.; Nematollahi, M.; Mahtabi, M.; Jahadakbar, A.; Elahinia, M. Self-heating and fatigue of additively manufactured NiTi. In Proceedings of the 2nd International Conference on Simulation for Additive Manufacturing, Pavia, Italy, 11-13 September 2019.

8. Nematollahi, M.; Baghbaderani, K.S.; Amerinatanzi, A.; Zamanian, H.; Elahinia, M. Application of NiTi in Assistive and Rehabilitation Devices: A Review. Bioengineering 2019, 6, 37. [CrossRef]

9. Morgan, N.B. Medical shape memory alloy applications-The market and its products. Mater. Sci. Eng. A 2004, 378, 16-23. [CrossRef]

10. Parsai, E.; Elliott, D.; Bayatimalayeri, P.; Elahinia, M. Rectal Retractor, A Novel Device for Sparing Rectum in Radiotherapy Applications of Pelvic Tumors. Med. Phys. 2019, 46, E199.

11. Parsai, E.I.; Jahadakbar, A.; Lavvafi, H.; Elahinia, M. A novel and innovative device to retract rectum during radiation therapy of pelvic tumors. J. Appl. Clin. Med. Phys. 2019, 20, 194-199. [CrossRef]

12. Amerinatanzi, A.; Zamanian, H.; Moghaddam, N.S.; Jahadakbar, A.; Elahinia, M. Application of the superelastic NiTi spring in ankle foot orthosis (AFO) to create normal ankle joint behavior. Bioengineering 2017, 4, 95. [CrossRef]

13. Malayeri, P.B.; Jahadakbar, A.; Elliottt, D.; Elahinia, M.; Parsai, E. A Novel Device to Retract Rectum during Radiotherapy Applications of Pelvic Tumors. Med. Phys. 2018, 45, E665.

14. Nematollahi, M.; Mehrabi, R.; Callejas, M.A.; Elahinia, H.; Elahinia, M. A two-way architectural actuator using NiTi SE wire and SME spring. Proc. SPIE 2018, 10595, 105952J9.

15. Andani, M.T.; Haberland, C.; Walker, J.M.; Karamooz, M.; Turabi, A.S.; Saedi, S.; Rahmanian, R.; Karaca, H.; Dean, D.; Kadkhodaei, M. Achieving biocompatible stiffness in NiTi through additive manufacturing. J. Intell. Mater. Syst. Struct. 2016, 27, 2661-2671. [CrossRef]

16. Saghaian, S.E.; Moghaddam, N.S.; Nematollahi, M.; Saedi, S.; Elahinia, M.; Karaca, H.E. Mechanical and shape memory properties of triply periodic minimal surface (TPMS) NiTi structures fabricated by selective laser melting. Biol. Eng. Med. 2018, 3. [CrossRef]

17. Dadbakhsh, S.; Speirs, M.; van Humbeeck, J.; Kruth, J.-P. Laser additive manufacturing of bulk and porous shape-memory NiTi alloys: From processes to potential biomedical applications. MRS Bull. 2016, 41, 765-774. [CrossRef]

18. Tan, C.; Li, S.; Essa, K.; Jamshidi, P.; Zhou, K.; Ma, W.; Attallah, M.M. Laser Powder Bed Fusion of Ti-rich TiNi lattice structures: Process optimisation, geometrical integrity, and phase transformations. Int. J. Mach. Tools Manuf. 2019, 141, 19-29. [CrossRef]

19. Namatollahi, M.; Jahadakbar, A.; Mahtabi, M.J.; Elahinia, M. Additive manufacturing (AM). In Metals for Biomedical Devices; Elsevier: Sawston, UK, 2019; pp. 331-353.

20. Zadpoor, A. Additively manufactured porous metallic biomaterials. J. Mater. Chem. B 2019, 7, 4088-4117. [CrossRef]

21. Mehrpouya, M.; Gisario, A.; Elahinia, M. Laser welding of NiTi shape memory alloy: A review. J. Manuf. Process. 2018, 31, 162-186. [CrossRef] 
22. Mehrpouya, M.; Dehghanghadikolaei, A.; Fotovvati, B.; Vosooghnia, A.; Emamian, S.S.; Gisario, A. The potential of additive manufacturing in the smart factory industrial 4.0: A review. Appl. Sci. 2019, 9, 3865. [CrossRef]

23. Rana, M.; Chui, C.H.K.; Wagner, M.; Zimmerer, R.; Rana, M.; Gellrich, N.-C. Increasing the accuracy of orbital reconstruction with selective laser-melted patient-specific implants combined with intraoperative navigation. J. Oral Maxillofac. Surg. 2015, 73, 1113-1118. [CrossRef]

24. Rotaru, H.; Schumacher, R.; Kim, S.-G.; Dinu, C. Selective laser melted titanium implants: A new technique for the reconstruction of extensive zygomatic complex defects. Maxillofac. Plast. Reconstr. Surg. 2015, 37, 12. [CrossRef]

25. Yang, W.; Choi, W.S.; Leung, Y.Y.; Curtin, J.P.; Du, R.; Zhang, C.; Chen, X.; Su, Y. Three-dimensional printing of patient-specific surgical plates in head and neck reconstruction: A prospective pilot study. Oral Oncol. 2018, 78, 31-36. [CrossRef] [PubMed]

26. Elahinia, M.; Moghaddam, N.S.; Andani, M.T.; Amerinatanzi, A.; Bimber, B.A.; Hamilton, R.F. Fabrication of NiTi through additive manufacturing: A review. Prog. Mater. Sci. 2016, 83, 630-663. [CrossRef]

27. Nematollahi, M.; Toker, G.; Saghaian, S.E.; Salazar, J.; Mahtabi, M.; Benafan, O.; Karaca, H.; Elahinia, M. Additive Manufacturing of Ni-Rich NiTiHf 20: Manufacturability, Composition, Density, and Transformation Behavior. Shape Mem. Superelasticity 2019, 5, 113-124. [CrossRef]

28. Van Humbeeck, J. Additive Manufacturing of Shape Memory Alloys. Shape Mem. Superelasticity 2018, 4, 309-312. [CrossRef]

29. Toker, G.P.; Nematollahi, M.; Saghaian, S.E.; Baghbaderani, K.S.; Benafan, O.; Elahinia, M.; Karaca, H.E. Shape memory behavior of NiTiHf alloys fabricated by selective laser melting. Scr. Mater. 2020, 178, 361-365. [CrossRef]

30. Zhou, Q.; Hayat, M.D.; Chen, G.; Cai, S.; Qu, X.; Tang, H.; Cao, P. Selective electron beam melting of NiTi: Microstructure, phase transformation and mechanical properties. Mater. Sci. Eng. A 2019, 744, 290-298. [CrossRef]

31. Biffi, C.A.; Bassani, P.; Nematollahi, M.; Moghaddam, N.S.; Amerinatanzi, A.; Mahtabi, M.J.; Elahinia, M.; Tuissi, A. Effect of Ultrasonic Nanocrystal Surface Modification on the Microstructure and Martensitic Transformation of Selective Laser Melted Nitinol. Materials (Basel) 2019, 12, 3068. [CrossRef]

32. Mehrpouya, M.; Gisario, A.; Rahimzadeh, A.; Nematollahi, M.; Baghbaderani, K.S.; Elahinia, M. A prediction model for finding the optimal laser parameters in additive manufacturing of NiTi shape memory alloy. Int. J. Adv. Manuf. Technol. 2019, 105, 4691-4699. [CrossRef]

33. Karaji, Z.G.; Speirs, M.; Dadbakhsh, S.; Kruth, J.-P.; Weinans, H.; Zadpoor, A.A.; Yavari, S.A. Additively manufactured and surface biofunctionalized porous nitinol. ACS Appl. Mater. Interfaces 2017, 9, 1293-1304. [CrossRef]

34. Katona, B.; Bognár, E.; Berta, B.; Nagy, P.; Hirschberg, K. Chemical etching of nitinol stents. Acta Bioeng. Biomech. 2013, 15, 3-8.

35. Shabalovskaya, S.A.; Anderegg, J.; Laab, F.; Thiel, P.A.; Rondelli, G. Surface Conditions of Nitinol Wires, Tubing, and As-Cast Alloys. The Effect of Chemical Etching, Aging in Boiling Water, and Heat Treatment. J. Biomed. Mater. Res. Part B Appl. Biomater. 2003, 65, 193-203. [CrossRef]

36. Pelton, R.; Dicello, J.; Miyazaki, S. Optimisation of processing and properties of medical grade Nitinol wire. Minim. Invasive Ther. Allied Technol. 2000, 9, 107-118. [CrossRef]

37. Mehrabi, R.; Kadkhodaei, M.; Ghaei, A. Numerical implementation of a thermomechanical constitutive model for shape memory alloys using return mapping algorithm and microplane theory. Adv. Mater. Res. 2012, 516, 351-354. [CrossRef]

38. Mehrabi, R.; Kadkhodaei, M.; Andani, M.T.; Elahinia, M. Microplane modeling of shape memory alloy tubes under tension, torsion, and proportional tension-torsion loading. J. Intell. Mater. Syst. Struct. 2015, 26, 144-155. [CrossRef]

39. Mehrabi, R.; Kadkhodaei, M. 3D phenomenological constitutive modeling of shape memory alloys based on microplane theory. Smart Mater. Struct. 2013, 22, 25017. [CrossRef]

40. Andani, M.T.; Alipour, A.; Eshghinejad, A.; Elahinia, M. Modifying the torque-angle behavior of rotary shape memory alloy actuators through axial loading: A semi-analytical study of combined tension-torsion behavior. J. Intell. Mater. Syst. Struct. 2013, 24, 1524-1535. [CrossRef] 
41. Andani, M.T.; Saedi, S.; Turabi, A.S.; Karamooz, M.R.; Haberland, C.; Karaca, H.E.; Elahinia, M. Mechanical and shape memory properties of porous Ni50. 1Ti49. 9 alloys manufactured by selective laser melting. J. Mech. Behav. Biomed. Mater. 2017, 68, 224-231. [CrossRef] [PubMed]

42. Hamilton, R.F.; Bimber, B.A.; Andani, M.T.; Elahinia, M. Multi-scale shape memory effect recovery in NiTi alloys additive manufactured by selective laser melting and laser directed energy deposition. J. Mater. Process. Technol. 2017, 250, 55-64. [CrossRef]

43. Saedi, S.; Moghaddam, N.S.; Amerinatanzi, A.; Elahinia, M.; Karaca, H.E. On the effects of selective laser melting process parameters on microstructure and thermomechanical response of Ni-rich NiTi. Acta Mater. 2018, 144, 552-560. [CrossRef]

44. Simka, W.; Kaczmarek, M.; Baron-Wiecheć, A.; Nawrat, G.; Marciniak, J.; Żak, J. Electropolishing and passivation of NiTi shape memory alloy. Electrochim. Acta 2010, 55, 2437-2441. [CrossRef]

45. ASTM International. ASTM F2063-18, Standard Specification for Wrought Nickel-Titanium Shape Memory Alloys for Medical Devices and Surgical Implants. 2018. Available online: www.astm.org (accessed on 15 December 2019).

(C) 2020 by the authors. Licensee MDPI, Basel, Switzerland. This article is an open access article distributed under the terms and conditions of the Creative Commons Attribution (CC BY) license (http://creativecommons.org/licenses/by/4.0/). 